Uluslararası Mühendislik

Cilt/Volume:11 Sayı/Issue:1 Ocak/January 2019

Araştırma Makalesi / Research Article

\title{
B $_{4}$ C Takviyeli Magnezyum (AZ91) Matrisli Kompozitlerin Mikroyapısal Karakterizasyonu
}

\section{Microstructural Variations In Cast $\mathrm{B}_{4}$ C-Reinforced Magnesium Matrix Composites}

\author{
Işıl Kerti*1 \\ ${ }^{1}$ Yıldız Teknik Üniversitesi, Metalurji ve Malzeme Müh. Bölümü, Davutpaşa Kampusu, 34210, Esenler, Istanbul,
}

Başvuru/Received: 01/02/2018

Kabul/Accepted: 05/06/2018

Son Baskı/Final Edition: 31/01/2019

\begin{abstract}
Öz
$\mathrm{B}_{4} \mathrm{C}$ takviyeli Magnezyum matrisli kompozit malzemelerden beklenen yüksek sertlik, aşınma direnci ve rijitlik özelliklerinin elde edilebilmesi için $\mathrm{B}_{4} \mathrm{C}$ ile sıvı magnezyum arasındaki ıslatma sorununun giderilmesi çok önemlidir. Bu çalışmada, \% 5 ve $\% 10 \quad \mathrm{~B}_{4} \mathrm{C}$ ile takviye edilmiş magnezyum matrisli (AZ91) kompozit malzemeler $750^{\circ} \mathrm{C}$ 'de karıştırma döküm yöntemi kullanılarak üretilmiştir. Üretilen kompozitlerin mikroyapı ve matris/takviye arayüzleri Tarama Elektron Mikroskobu (SEM) kullanılarak, matris/takviye arasındaki reaksiyon tabakası EDS analizi ve X-ışıı haritalaması ile karakterize edilmiștir. Yüksek çözünürlüğe sahip FEG-SEM ile yapılan mikroyapısal inceleme sonucunda, arayüzeyde oluşan ince tabakanın Mn-C ve Al-B bileşiklerinden oluştuğu belirlenmiştir.
\end{abstract}

\section{Anahtar Kelimeler}

“Kompozit, Magnazyum, Arayüzey, Bor karbür, Karıştırma döküm, AZ91"

\begin{abstract}
It is very important to overcome the wetting problem between $\mathrm{B}_{4} \mathrm{C}$ and liquid magnesium so that the high hardness, wear resistance and stiffness properties expected from $\mathrm{B}_{4} \mathrm{C}$ reinforced $\mathrm{Mg}$ matrix composite materials can be obtained. In the present work, Magnesi1um matrix (AZ91) composites reinforced with 5 and 10\%(wt.) $\mathrm{B}_{4} \mathrm{C}_{\mathrm{P}}$ were produced by using stir casting method at $750^{\circ} \mathrm{C}$. Microstructure and matrix/reinforcement interfaces of produced composites were have been characterized using scanning electron microscopy (SEM) studies. The reaction layer between matrix/reinforcement was also characterized with EDS analysis and X-ray mapping. It was found from the microstructural observations by high resolution field emission gun SEM (FEG-SEM) that the wetting improved by the formation of very thin Mn-C and Al-B reaction layers.
\end{abstract}

\section{Key Words}

“Composite, Magnesium, Interface, Boron Carbide, Stir Casting, AZ91” 


\section{GIRIȘ}

Malzeme tasarımında, düşük maliyet, hafiflik, tokluk ve çevresel etki gibi kriterler, her geçen gün daha fazla önem kazanmaktadır, günümüzün geleneksel malzemeleri bu ihtiyaçların karşılanmasında yetersiz kaldığı için daha üstün özelliklere sahip kompozit malzemeler üretilmeye başlanmış ve bu konuda hızı bir gelişme sürecine girilmiştir. Özellikle motorlu taşıt üreticilerinin yakıt tüketimini ve karbon emisyonunu düşürmeyi hedeflemeleri nedeniyle, taşıt araçlarında kompozit malzemeler kullanımı, sahip oldukları yüksek mukavemet/hafiflik oranı nedeniyle geleneksel malzemelere göre daha önemli hale gelmiştir. (Tokaji, K., (2005), Lopez, V.H. ve arkadaşları (2003)).

Metal matrisli kompozitlerde (MMK) SiC, $\mathrm{Al}_{2} \mathrm{O}_{3}, \mathrm{~B}_{4} \mathrm{C}$, $\mathrm{TiC}_{\mathrm{C}} \mathrm{Si}_{3} \mathrm{~N}_{4}$ gibi malzemeler takviye malzemesi olarak kullanılmaktadır (Shorowordi, K. M. ve arkadaşları (2003), Rajan, T. P. D. ve arkadaşları (1998), Kerti, I., (2005)). Metallerin süneklik ve tokluk, seramiklerin yüksek mukavemet ve yüksek elastik modülü özelliklerinin birleştirilmeleri neticesinde son derece önemli mühendislik malzemeleri olan MMK'ler ortaya çıkmaktadır (Özdin, K., (2006), Toptan, F., (2011)). Geçiş metallerinin karbürlerinin, borürlerinin ve nitrürlerinin sslatılabilirliklerinin, kovalent ve iyonik bağlı seramiklere göre daha yüksek olduğu bilinmektedir (Kennedy, A.R., Karantzalis, A.E., (1999)).

$\mathrm{B}_{4} \mathrm{C}$ sahip olduğu yüksek rijitlik ve sertlik, yüksek darbe ve aşınma direnci, yüksek ergime sıcaklığı, yüksek kimyasal direnç, üstün mekanik ve fiziksel özellikleri sayesinde MMK ler için cazip bir takviye malzemesidir (Zhang, H. ve arkadaşları (2004), Aizenshtein, M. ve arkadaşları, (2005), Jung, J., Kang, S., (2004), Zhu, X. Ve arkadaşları (2008), Shrestha, N.K. ve arkadaşları (2005), Khan, K.B., Kutty, T.R.G., Surappa, M.K., (2006)). Ancak, $\mathrm{B}_{4} \mathrm{C}$ tozlarının maliyetinin, $\mathrm{SiC}$ veya $\mathrm{Al}_{2} \mathrm{O}_{3}$ gibi takviye malzemelerine göre daha yüksek olması, $\mathrm{B}_{4} \mathrm{C}$ takviyeli $\mathrm{MMK}$ 'ler üzerinde yapılan araştırmaların kısmen sınırlı kalmasına yol açmaktadır.

Magnezyum ve alaşımları günümüzde modern hafif yapılar için önemli bir malzeme olarak kabul edilmektedir. Magnezyumun 1,7 $\mathrm{g} / \mathrm{cm}^{3}$ lük düşük yoğunluğu ile alüminyumla hemen hemen aynı dayanım değerine sahip olmasına ragmen ağırlık olarak alüminyumdan \%36, demirden \%78 daha hafiftir. Bu nedenle magnezyum matrisli kompozitler (Mg-MMK) düşük yoğunluk ve yüksek dayanımları sayesinde özellikle ağıllık tasarrufu gerektiren otomotiv ve havacılık uygulamaları için cazip hale gelmektedir (Atalay O., (2006)).

Günümüzde, sağladığı birçok avantaj ile kullanım alanları giderek artan magnezyum esaslı kompozit malzemeler, ticari saflıktaki magnezyum ve magnezyum alaşımlarından daha yüksek mekanik özelliklere sahiptir (Demir, A., (2006)). Magnezyumun düşük elastite modülü ve artan sıcaklıkla azalan dayanımı kullanımını sınırlarken, $\mathrm{Al}_{2} \mathrm{O} 3, \mathrm{~B}_{4} \mathrm{C}, \mathrm{SiC}$ ya da $\mathrm{TiC}$ gibi farklı partiküllerin takviyesi ile bu özellikler iyileştirilebilmektedir.

$\mathrm{Bu}$ çalışmada üretilen $\mathrm{Mg}-\mathrm{B}_{4} \mathrm{C}$ kompozitlerinde, arayüzeyde üretim sırasında in-situ olarak oluşan $\mathrm{Mn}$-C ve Al-B reaksiyon tabakasının magnezyumun bor karbür üzerindeki ıslatılabilirliğini artırdığı ve bu sayede kompozitlerin kısmen yüksek partikül ilave verimi ile (yaklaşık \%85) üretilebildiği sonucuna varılmıştır.

\section{MALZEME VE YÖNTEM}

Çalışmada, matris malzemesi olarak, kimyasal bileşimi Tablo 1'de verilen AZ91D magnezyum döküm alaşımı; takviye malzemesi olarak, Alfa Aesar (USA) dan temin edilen ortalama partikül boyutu $32 \mu \mathrm{m}$ ve spesifik yüzey alanı $0,253 \mathrm{~m}^{2} / \mathrm{g}$ olan $\mathrm{B}_{4} \mathrm{C}$ partikülleri kullanılmıştır.

Tablo 1. AZ91D Alaşımının Kimyasal Bileşimi

\begin{tabular}{ccccccccc} 
Alaşım & Al & Mn & Zn & Si & Cu & Ni & Fe & Be \\
\hline AZ91D & $8.5-9.5$ & $0.2-0.3$ & $0.45-$ & 0.05 & 0.025 & 0.01 & 0.04 & 0.0015 \\
& & & 0.90 & & & & &
\end{tabular}

Kompozit malzemelerin üretimi karıştırmalı döküm (vortex) yöntemi ile koruyucu atmosferli indüksiyon firını (Şekil 1) kullanılarak gerçekleştirilmiştir. Ergitme aşamasında kontaminasyonun engellenmesi amacıyla grafit pota ve karıştırıcılar bor nitrür ile kaplanmıştır. Ergitme işlemi argon gazı altında gerçekleştirilirken, karıştırma işlemi için dört kanatlı paslanmaz çelikten imal edilmiş karıştırıcı kullanılmıştır. Yapılan tüm dökümlerde, matris malzemesi olarak 450 gram magnezyum döküm alaşımı (AZ91D) kullanılmıştır. $\mathrm{B}_{4} \mathrm{C}$ tozları ilave edilmeden önce, yüzeylerindeki kirliliğin giderilmesi, absorbe olmuş gazların ayrılması ve nemin giderilmesi için $105^{\circ} \mathrm{C}$ 'ta 2 saat ön 1sıtılmıştır. Yüksek karıştırma hızlarında gaz çözündürme oranı arttığından karıştırma hızı olarak vorteksin oluştuğu 500 devir/dakika seçilmiştir. Ergiyik, silindirik şekilli önceden $105^{\circ} \mathrm{C}$ sıcaklığa 1sıtılmış kokil kalıba dökülmüştür. 
Döküm parçalarından numuneler alınmış ve elmas zımpara ve süspansiyonlar ile metalografik incelemeler için hazırlanmıştır. Mikroyapılar, EDX donanımlı JEOL JSM-5410 ve JEOL JSM 7000F FEG-SEM tarama elektron mikroskobları (SEM) kullanılarak incelenmiş̧tir.

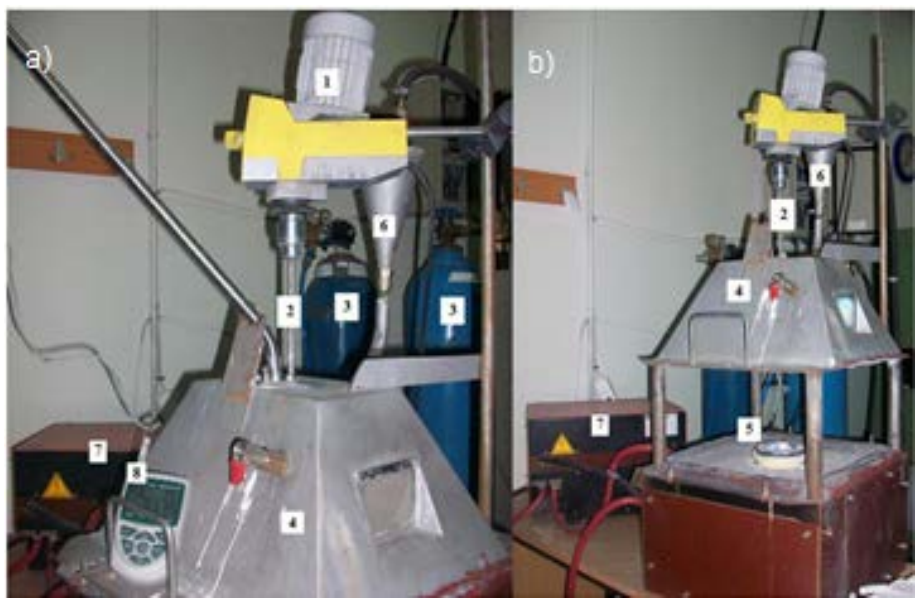

Şekil 1. Özel tasarım indüksiyon fırını a) Deney düzeneğinin kapalı görünümü b) Deney düzeneğinin açık görünümü (1. Mekanik karıştırıcı, 2. Karıştırıcı şaft 3. Argon tüpü, 4. Fırın kapağı, 5. BN Kaplı grafit pota, 6. Takviye besleyici 7. Güç Ünitesi, 8. Sıcaklık kontrolü (Termokupl))

\section{BULGULAR VE TARTIŞMA}

Döküm numunelerinin mikroyapıları incelendiğinde, Şekil 2'de görüldüğü gibi, takviye malzemesinin, yapı içinde homojen olarak dağıldığı belirlenmiş, ancak az da olsa yer yer topaklanmaların ve porozitelerin olduğu görülmüştür (Şekil 3).

Karıştırmalı dökümün başarılı olabilmesi için ıslanabilirliğin iyi olması gerekmektedir. Artan viskozite nedeniyle partiküllerin ergiyik içerisine ilavesinde bazı zorluklar ortaya çıkmakta, partikül topaklanması veya dağılımının homojen olmaması gibi mikroyapısal homojensizlikler oluşabilmektedir. Karıştırma hızı, karıştıııı şekli, boyutu ve ergiyik içerisindeki konumu gibi çeşitli etkenler MMK'lerin mikroyapısal dolayısıyla mekanik özelliklerini etkilemektedir.

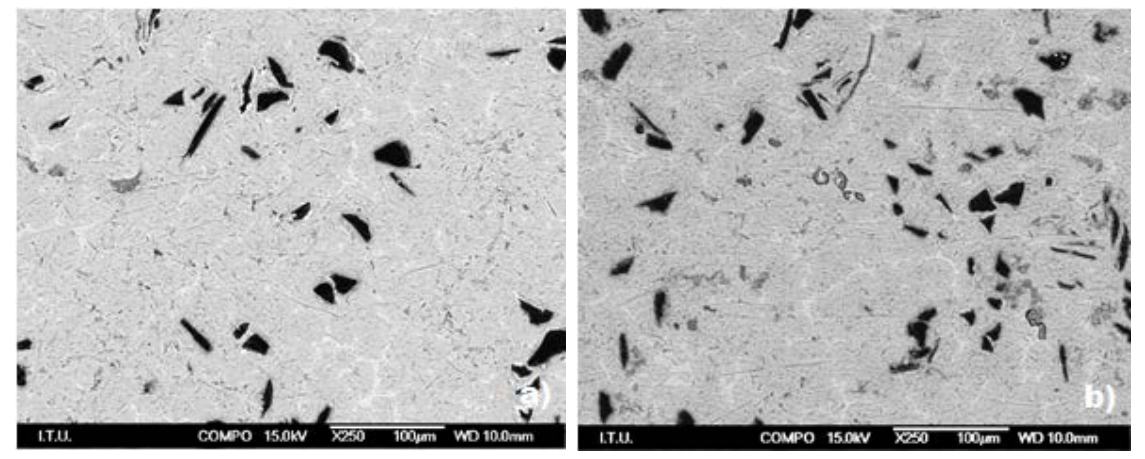

Şekil 2. a) \% $5 \mathrm{~B}_{4} \mathrm{C}$ and b) $\% 10 \mathrm{~B}_{4} \mathrm{C}$ hacim oranına sahip Mg-MMK lara ait SEM görüntüleri

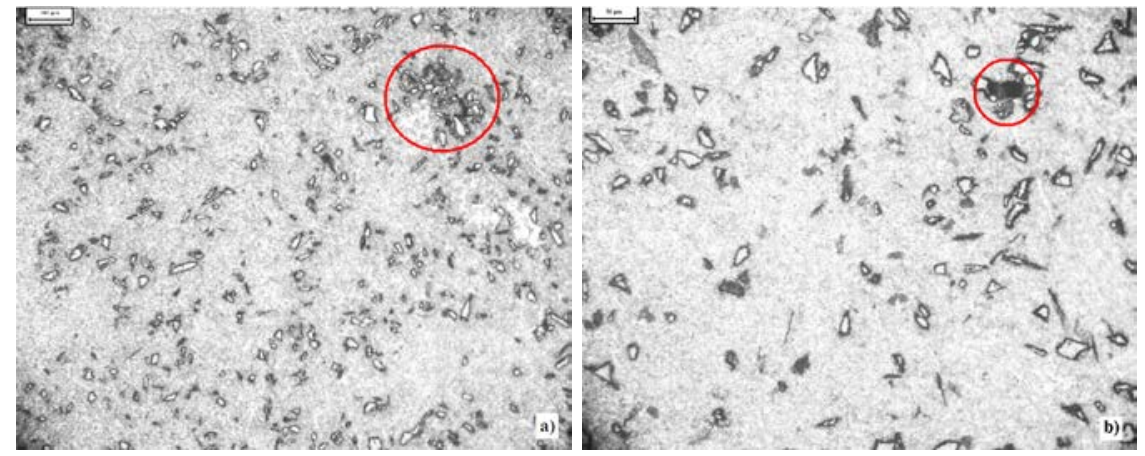

Şekil 3. \%10 B ${ }_{4} \mathrm{C}$ takviyeli Mg-MMK'e ait 1şık mikroskobu görüntüleri a) Topaklanma b) Porozite

Yüksek büyütmelerde yapılan detaylı inceleme ve analizlerde, $\mathrm{B}_{4} \mathrm{C}$ partiküllerinin $\mathrm{Mn}-\mathrm{Al}-\mathrm{C}$ bileşikleri tarafindan çevrelendiği belirlenmiştir. Şekil 4'de \% 10 B 4 C içeren Mg-MMK'e ait FEG-SEM görüntüsü ve X-ışını haritası incelendiğinde partikül matris 
arayüzeyinde Mn ve Al'ca zengin ince bir tabakanın varlığı görülmektedir. Şekil 5'de verilen çizgi analizi verileri de bu sonucu desteklemektedir. .
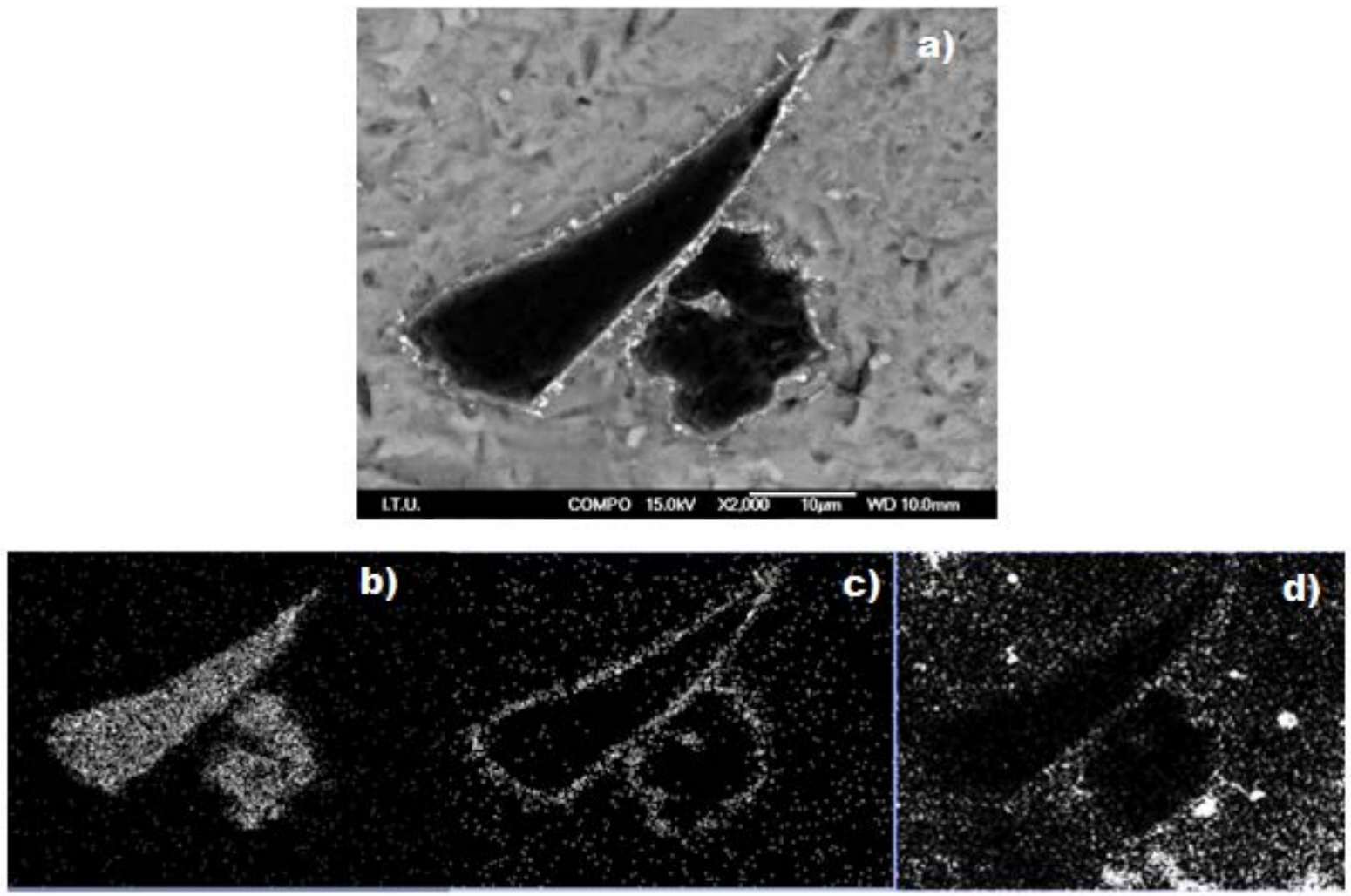

Şekil 4. a) $\mathrm{B}_{4} \mathrm{C}$ ilavesiyle üretilen kompozit numuneye ait SEM görüntüsü ve b) B, c) Mn, d) Al elementlerine ait X-1şını haritaları
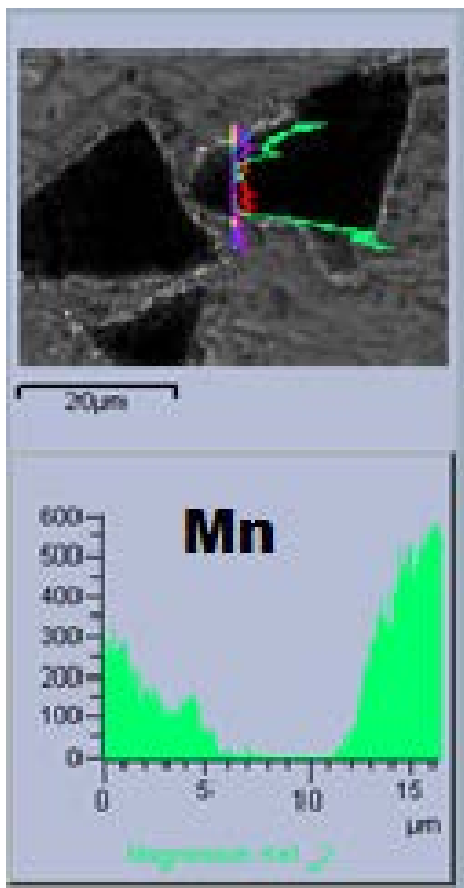
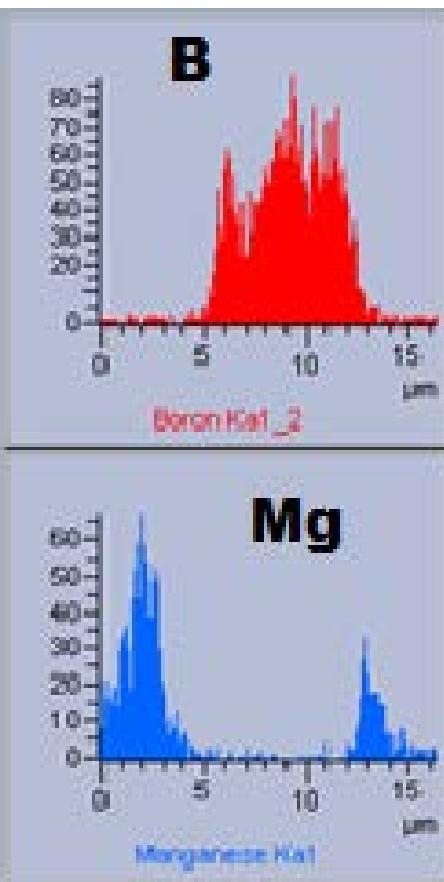
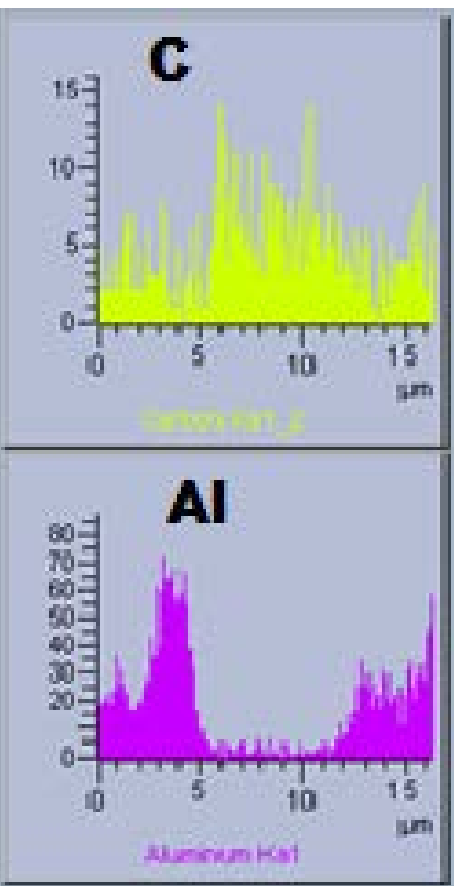

Şekil 5. \% $5 \mathrm{~B}_{4} \mathrm{C}$ takviyeli kompozitte matris-arayüzey-takviye boyunca çizgi analizi ve SEM görüntüsü

Mg-Al-Mn-Zn-B-C sisteminde yapılan taramalarda üçlü veya dörtlü bir bileşiğe rastlanmazken, sistemde olması muhtemel ikili bileşikler şunlardır: $\mathrm{AlB}_{2}, \mathrm{AlB}_{12}, \mathrm{Al}_{4} \mathrm{C}_{3}, \mathrm{~B}_{4} \mathrm{C}, \mathrm{MgB}_{2}, \mathrm{MgB}_{4}, \mathrm{MgB}_{12}, \mathrm{MgC}_{2}, \mathrm{Mg}_{2} \mathrm{C}_{3}, \mathrm{MgZn}_{2}, \mathrm{Mn}, \mathrm{MnB} \mathrm{MnB}_{2}, \mathrm{Mn}_{2} \mathrm{~B}, \mathrm{Mn}_{3} \mathrm{~B}_{4}$, $\mathrm{MnC}_{2}, \mathrm{Mn}_{3} \mathrm{C}, \mathrm{Mn}_{7} \mathrm{C}_{3}, \mathrm{Mn}_{15} \mathrm{C}_{4}$ ve $\mathrm{Mn}_{23} \mathrm{C}_{6}$ (Roine, A., (2002)). Bu bileşikler ile HSC Chemistry programı kullanılarak oluşturulan Ellingham diyagramı Şekil 6'da verilmiştir. 


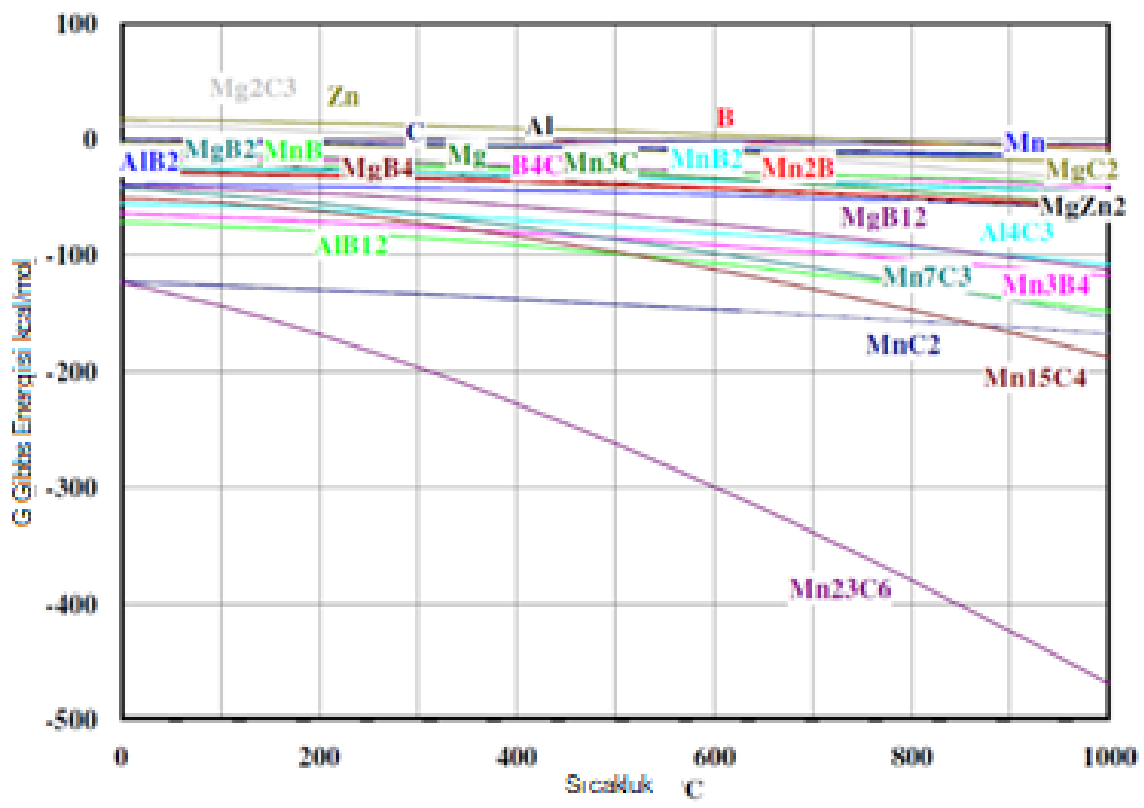

Şekil 6. Mg-Al-Mn-Zn-B-C'de ikili bileşiklerin Ellingham diyagramı (Roine, A., (2002))

Ellingham diyagramına göre, sistemde en düşük Gibbs serbest enerjisine $(\Delta \mathrm{G})$ sahip bileşiklerin Mn-C bileşikleri olduğu görülmektedir. Diyagrama göre, $\mathrm{AlB}_{12}$ bileşiği de nispeten düşük serbest enerjiye sahiptir. Şekil 4 ve Şekil 5'de verilen harita ve analizler incelendiğinde, alaşımdaki miktarı oldukça düşük olmasına rağmen $(\% 0,2-0,3)$ arayüzeyde yüksek miktarda Mn'a rastlanmıştır. Bunun yanısıra arayüzeyde Al miktarının matrise göre daha yüksek olduğu görülmektedir. Dolayısıyla, bu termodinamik öngörüler ve EDS analizleri incelendiğinde arayüzeyin genel olarak Mn-C fazlarından oluştuğu ve bir miktar da $\mathrm{AlB}_{12}$ fazı içerdiği düşünülmektedir

Hacimce \%5 $\mathrm{B}_{4} \mathrm{C}$ takviyeli Mg-MMK malzemede matris-takviye arayüzeyinden yüksek büyütmede alınan SEM görüntüleri Şekil 7'de ve üç farklı noktadan alınan EDS analizleri Şekil 8'de verilmiştir.

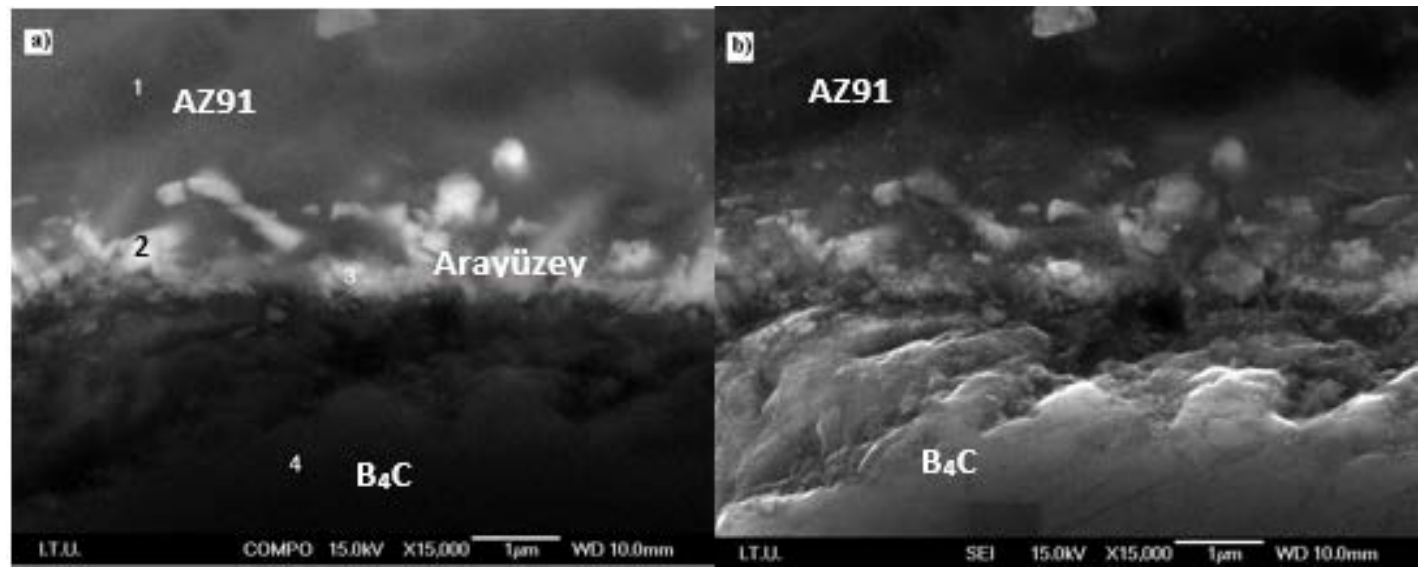

Şekil 7. \%5 B4C takviyeli Mg-MMK malzemede matris-takviye arayüzey a) COMPO, b) SE SEM görüntüleri
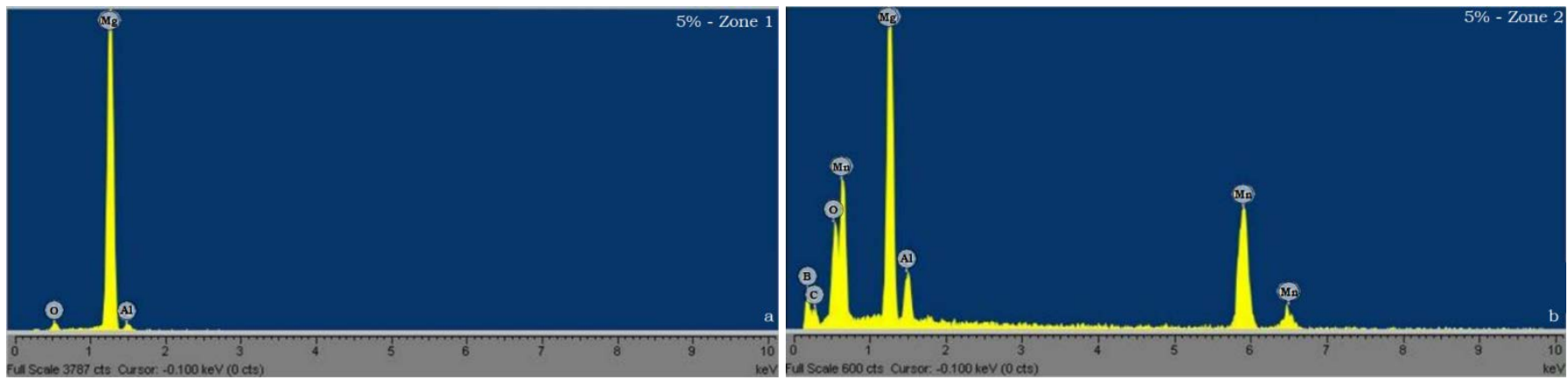

Şekil 8. Şekil 7 de verilen görüntüde a) 1 b) 2 ve 3 noktalardan alınan EDS analizleri 
"1" noktasından alınan (Şekil 7) EDS analizi, Mg ve Al elementlerinin bulunduğu bu alanın matris olduğunu göstermektedir. "2”" ve “3”'ile işaretli bölgelerden alınan EDS analizinde $\mathrm{Mg}, \mathrm{Al}, \mathrm{Mn}, \mathrm{C}, \mathrm{B}$ ve Oksijen elementlerinin varlığı tespit edilmiştir. Mg, Al ve Mn elementlerinin kaynağı döküm alaşımıdır. Mg’un oksijene olan yüksek afinitesinden dolayı yapılan EDS analizinde oksijenin tespit edilmesi beklenen bir durumdur. \%10 $\mathrm{B}_{4} \mathrm{C}$ içeren kompozit malzemede de benzer sonuçlar elde edilmiştir.

\section{SONUÇLAR}

Magnezyum matrisli $\mathrm{B}_{4} \mathrm{C}$ partikül takviyeli kompozitler sıvı faz üretim yöntemleriyle üretilmiş ve mikroyapısal özellikleri incelenmiştir.

Hacimce $\% 5$ ve $\% 10 \mathrm{~B}_{4} \mathrm{C}$ partikül takviyeli Mg matrisli kompozitler sirasıly $\% 4,2$ ve \%8,58 deneysel hacim oranı ve \%84,07 ve $\% 85,08$ partikül ilave verimi ile üretilmiştir.

Mikroyapı incelemelerinde $\mathrm{B}_{4} \mathrm{C}$ partiküllerinin matris içerisinde homojen bir şekilde dağılım gösterdiği, ancak az da olsa topaklanma ve porozite olduğu gözlemlenmiştir.

Mg-Al-Mn-Zn-B-C sisteminde yapılan termodinamik taramalar ve matris/takviye arayüzeyinde gerçekleştirilen EDS analizlerine dayanarak üretim sırasında arayüzeyde $\mathrm{Mn}-\mathrm{Al}-\mathrm{C}$ bileşiklerince zengin bir reaksiyon tabakası oluştuğu sonucuna varılmıştır. Bu reaksiyon tabakasının ıslatılabilirliği arttırdığı ve kompozitlerin nispeten yüksek partikül ilave verimi ile üretilebilmesine olanak sağladığı düşünülmektedir.

\section{REFERANSLAR}

Aizenshtein, M., Froumin, N., Shapiro-Tsoref, E., Dariel, M.P., Frage, N., (2005), Wetting and interface phenomena in the B4C/(Cu-B-Si) system, Scripta Materialia 53, 1231-1235, doi:10.1016/j.scriptamat.2005.08.006

Atalay O., (2006), Magnezyum ve Alaşımlarının Konstrüksüyon Malzemesi Olarak Otomotivde Kullanımı, Yüksek Lisans Tezi, İTÜ Fen Bilimleri Enstitüsü, İstanbul.

Demir, A., (2006), Metaller Arası Bileşik Mg2Si Takviyeli AZ91/Mg2Si Kompozit Malzemelerin Geliştirilmesi, Yüksek Lisans Tezi, Gazi Üniversitesi Fen Bilimleri Enstitüsü, Ankara.

Jung, J., Kang, S., (2004), Advances in Manufacturing Boron Carbide-Aluminum Composites, J. Am. Ceram. Soc., 87 [1] 47-54, doi: 10.1111/j.1551-2916.2004.00047.x

Kennedy, A.R., Karantzalis, A.E., (1999), The incorporation of ceramic particles in molten aluminium and the relationship to contact angle data, Materials Science and Engineering A264, 122-129, doi:10.1016/S0921-5093(98)01102-2

Kerti, I., (2005), Production of TiC reinforced-aluminum composites with the addition of elemental carbon, Materials Letters, 59, 3795 - 3800, doi:10.1016/j.matlet.2005.06.032

Khan, K.B., Kutty, T.R.G., Surappa, M.K., (2006), Hot hardness and indentation creep study on Al-5\% Mg alloy matrix-B4C particle reinforced composites, Materials Science and Engineering A 427, 76-82, doi:10.1016/j.msea.2006.04.015

Lopez, V.H., Scoles, A., Kennedy, A.R., (2003), The thermal stability of TiC particles in an Al7wt.\%Si alloy, Mater. Sci. \& Eng. A, 356, 316-325, doi:10.1016/S0921-5093(03)00143-6

Özdin, K., (2006), Production of aluminium based SiC-reinforced composite materials and investigation of their wear properties, PhD Thesis, Gazi University. (in Turkish)

Rajan, T. P. D., Pillai, R.M., Pai, B. C., (1998), Review, Reinforcement coatings and interfaces in aluminium metal matrix composites, Journal of Materials Science Vol.33, 3491-3503, doi: 10.1023/A:1004674822751

Roine, A., (2002), Outokumpu HSC Chemistry for Windows, Ver. 5.1, 1999, Outokumpu Research Oy: Pori, Finland.

Shorowordi, K. M., Laoui, T., Haseeb, A. S. M. A., Celis, J. P., Froyen, L., (2003), Microstructure and interface characteristics of B4C, SiC and Al2O3 reinforced Al matrix composites: a comparative study, Journal of Materials Processing Technology, 142, 738-743, doi:10.1016/S0924-0136(03)00815-X

Shrestha, N.K., Kawai, M., Saji, T., (2005), Co-deposition of B4C particles and nickel under the influence of a redox-active surfactant and anti-wear property of the coatings, Surface \& Coatings Technology 200, 2414- 2419, doi: 10.1016/j.surfcoat.2004.08.192 
Tokaji, K., (2005), Effect of stress ratio on fatigue behaviour in SiC particulate-reinforced aluminium alloy composite, fatigue fract. eng. mater., 28, 539-545 , doi: 10.1111/j.1460-2695.2005.00894.x

Toptan, F., (2011), Production of high wear resistant B4C particle reinforced aluminium matrix composites, PhD Thesis, Yildiz Technical University. (in Turkish)

Zhang, H., Ramesh, K. T., Chin, E.S.C., (2004), High Strain Rate Response of Aluminium 6092/B4C Composites, Materials Science and Engineering, A 384, 26-34, doi:10.1016/j.msea.2004.05.027

Zhu, X., Dong, H., Lu, K., (2008), Coating different thickness nickel-boron nanolayers onto boron carbide particles, Surface \& Coatings Technology 202, 2927-2934, doi:10.1016/j.surfcoat.2007.10.021 